\title{
Aperfeiçoamento de Estratégias para Intervenção Institucional e Comunitária
}

\author{
Nicolau Tadeu Arcaro ${ }^{1}$ \\ Instituto Brasileiro de Geografia e Estatística, Unidade Estadual de São Paulo, \\ São Paulo, Brasil \\ Eda Terezinha de Oliveira Tassara \\ Departamento de Psicologia Social e do Trabalho da Universidade de São Paulo, \\ São Paulo, São Paulo, Brasil
}

\begin{abstract}
Resumo
O objetivo da investigação aqui relatada foi examinar procedimentos para trabalho com populações de baixa renda e preparo de pessoas que prestam assistência a essas populações. O relato apresenta uma descrição das intervenções implementadas, assim como uma avaliação de tais intervenções com base, principalmente, em depoimentos dos participantes e na produção de trabalhos socioambientais gerada por esses participantes. Vinculada ao projeto "Coletivo Educador da Região Norte da Cidade de São Paulo", que envolvia a formação de grupos participativos de líderes comunitários e de profissionais que assistiam a comunidades carentes, a pesquisa implementou e avaliou as estratégias adotadas para a constituição e o acompanhamento da maioria de tais grupos. Os resultados, verificados por meio de relatórios de atividade, questionários de avaliação e observação direta, mostraram-se bastante positivos. Foram estruturados e trabalhados, no presente estudo, três grupos de profissionais da área educacional e um de líderes comunitários. Seus participantes, além de avaliarem as intervenções implementadas favoravelmente, realizaram 18 projetos socioambientais, o que evidenciou ainda mais a eficácia da estratégia empregada.
\end{abstract}

Palavras-chave: População de baixa renda, comunidade, metodologia participativa, educação ambiental, imagens mentais.

\section{Improvement of Institutional and Community Intervention Strategies}

\begin{abstract}
The aim of the current study was to examine procedures for working with low-income populations and preparation of people who provide assistance to these populations. The report presents a description of the interventions implemented, and an evaluation of such interventions based mainly on testimonies of the participants and the production of social-environmental works generated by these participants.
\end{abstract}

Endereço para correspondência: Rua Pamplona, 346/62, Bela Vista, São Paulo, SP, Brasil 01405-000. E-mail: nicolau.ta@gmail.com

Este trabalho foi realizado como pesquisa para pós-doutorado, com supervisão da Profa. Eda T. O. Tassara. Foi subvencionado pelo Instituto Brasileiro de Educação, Ciência e Cultura da Organização das Nações Unidas para a Educação, a Ciência e a Cultura (IBECC/UNESCO), mediante recursos concedidos pelo Ministério do Meio Ambiente para o projeto "Coletivo Educador da Região Norte da Cidade de São Paulo", do qual fez parte. O primeiro autor deseja agradecer o apoio da Profa. Eda e a colaboração dos colegas Sandra M. P. Vichietti, Ive N. Sassano, Luciana P. Gil, Marcela M. Mejias e Rodrigo R. S. Peppe, do projeto Coletivo Educador. 
Associated to the project "Coletivo Educador da Região Norte da Cidade de São Paulo", that involved the structuring of participative groups of community leaders and of professionals who used to assist poor communities, the research implemented and evaluated the interventions adopted to organize and accompany most of such groups. The results, verified through activity reports, evaluation questionnaires and direct observation, were very positive. Three groups of education professionals and one of community leaders were structured. Their participants, in addition to assessing the implemented interventions positively, generated 18 social-environmental projects, what showed even more the effectiveness of the employed strategy.

Keywords: Low-income population, community, participative methodology, environmental education, mental imagery.

\section{Mejoramiento de las Estrategias de Intervención Institucional y Comunidad}

\section{Resumen}

El objetivo de la investigación informada aquí fue examinar los procedimientos para el trabajo con poblaciones de bajos recursos y preparar a las personas que prestan asistencia a estas poblaciones. El informe presenta una descripción de intervenciones implementadas, así como una evaluación de tales intervenciones basada principalmente en testimonios de los participantes y en la producción de trabajos socio-ambientales generada por estos participantes. Vinculado al proyecto "Colectivo Educador en el Norte de la Ciudad de São Paulo “, que implica la formación de grupos participativos de líderes comunitarios y profesionales que asistieron a las comunidades pobres, la investigación ha implementado y evaluado las estrategias adoptadas para el establecimiento y seguimiento de la mayoría de esos grupos. Los resultados verificados a través de informes de actividades, cuestionarios de evaluación y observación directa, fueron muy positivos. En el presente estudio, fueron estructurados y si trabajó tres grupos de profesionales de la educación y un grupo de líderes de la comunidad. Sus participantes, además de evaluar favorablemente las intervenciones implementadas, han hecho 18 proyectos socio-ambientales, lo que puso de manifiesto aún más la eficacia de la estrategia empleada.

Palabras clave: Población de bajos recursos, comunidad, metodología participativa, educación ambiental, imágenes mentales.

O Brasil apresenta grande contingente populacional em situação de pobreza. Embora o nível tecnológico do país venha se sofisticando, políticas recessivas, e o próprio aperfeiçoamento da tecnologia, levaram à diminuição dos postos de trabalho e direitos do trabalhador (Alves, 2004). Tal situação, cabe acrescentar, aumenta a vulnerabilidade à incidência de distúrbios psicológicos, senão generalizadamente, ao menos em certos grupos sociais (Charlesworth, 2005). Sendo assim, é preciso pensar em meios de atender às grandes e diversificadas necessidades dos amplos estratos populacionais de baixa renda do país. Entretanto, as práticas mais disseminadas da psicologia mostram limitações significativas.
A assistência psicológica tradicional é individualizada e prolongada, o que a torna dispendiosa e resolutiva apenas a longo prazo. E essa assistência foi elaborada principalmente no trabalho com estratos sociais relativamente abastados, tendo eficiência ainda mais limitada com populações carentes (Arcaro, Herzberg, \& Trinca, 1999). Além disso, tais populações têm à disposição recursos assistenciais bastante reduzidos, situação que exige estratégias que possam beneficiar amplo número de pessoas, não sendo este o caso dos procedimentos tradicionais da psicologia.

Ademais, as populações desprivilegiadas apresentam problemas urgentes e multifaceta- 
dos que estão, amiúde, além do alcance das intervenções mais utilizadas pela psicologia. Tais problemas podem abranger aspectos biológicos, psicológicos, familiares, sociais, econômicos e ambientais. Envolvem diversas associações entre, por exemplo, doenças, uso de drogas, distúrbios emocionais, conflitos familiares, desemprego, problemas de integração social e moradia precária. Como no caso de certos moradores de favela, pertencentes a famílias desestruturadas, que não conseguem arrumar trabalho e, por tudo isso, desenvolvem quadros de severa ansiedade, começam a usar drogas e adoecem fisicamente.

Deve-se mencionar, ainda, que a atuação psicológica convencional apóia-se, sobretudo, na comunicação verbal de estados subjetivos e se vale, com frequência, de conceitos abstratos, como os de processo inconsciente, auto-realização, ego e outros que muitos integrantes dessas populações não manejam bem (Arcaro, 1997). Afora esses entraves, observa-se que muitas das pessoas de baixa renda têm dificuldade de se locomover até os locais de atendimento, que costumam ficar longe de suas residências. Isso, em se tratando de atendimentos frequentes como os exigidos pelas práticas tradicionais da psicologia, impõe a essas pessoas um tempo de transporte incompatível com sua jornada de trabalho e, para aquelas com maiores limitações econômicas, um custo financeiro excessivamente oneroso (Arcaro et al., 1999).

As circunstâncias acima expostas requerem que a psicologia brasileira aperfeiçoe estratégias mais acessíveis, ágeis e que permitam maior amplitude de cobertura (Arcaro et al., 1999). Várias propostas nesse sentido vêm sendo implementadas e avaliadas. A maioria é endereçada a populações carentes, ou pode ser utilizada com esse tipo de população.

Uma dessas propostas é a de intervenções breves, que possibilitam efeitos rápidos e abarcam número relativamente grande de indivíduos (e. g. Arcaro, 1997). Outras propostas que podem aumentar a abrangência numérica dos recursos assistenciais são as de trabalho grupal (e. g. Mendonça, 2005; Silva, 2002), utilização de paraprofissionais (e. g. Gomes, 2004) e prevenção (e.g. Vizzotto, 2003).
Ainda podem ser citadas intervenções familiares (e. g. Costa, 1997), comunitárias (e.g. Palha, 2001; Vizzotto, 2003), estratégias multidisciplinares (e.g. Garcia \& Jorge, 2006) e educação ambiental para o desenvolvimento social ecologicamente sustentável (e.g. Wiesenfeld, 2001). Como diversos fatores (biológicos, psíquicos, familiares, sociais, econômicos, ambientais, etc.) podem estar presentes nas problemáticas dos indivíduos e comunidades, tais trabalhos possibilitam mais ampla cobertura das dificuldades encontradas que os procedimentos convencionais. Por exemplo, Costa (1997) relatou como reuniões multifamiliares, realizadas com uma comunidade, puderam não apenas gerar resultados psicologicamente terapêuticos mas, simultaneamente, melhorar a organização comunitária, levando à articulação de um grupo de pessoas para produção de recursos financeiros. Já Palha (2001), usando como metodologia o Discurso do Sujeito Coletivo, que visa o resgate da fala do social a partir das idéias centrais e expressões-chave dos discursos individuais, obteve resultados indicativos da eficácia de um programa de intervenção comunitária em termos de conscientização, participação política e formação de rede de suporte social na comunidade.

Ainda a respeito de intervenções comunitárias, Vizzotto (2003) discorre sobre como o atendimento clínico na comunidade pode, inclusive, ter efeito preventivo. Por sua vez, Garcia e Jorge (2006) enfocam estratégia multidisciplinar, investigando questões ligadas ao trabalho em um Centro de Assistência Psicossocial (Caps). E Wiesenfeld (2001), abordando a questão da educação ambiental, afirma que o desenvolvimento sustentável não pode se atrelar apenas à problemática ambiental, mas precisa também abranger o desenvolvimento socioeconômico.

Além disso, certos autores também propõem atendimento no local de moradia das populações desprivilegiadas, tendo em vista as dificuldades dessas populações com transporte. Ademais, acredita-se que o atendimento in loco possibilita a observação mais próxima dos problemas abordados (Arcaro et al., 1999).

Finalmente, muito se tem explorado, em anos recentes, sobre metodologias participati- 
vas (Costa, 1997; Gomes, 2004; Molina, 2007; Romme, 2004; Silva, 2002). Tais estratégias, visando promover a autonomia dos assistidos, buscam seu engajamento tanto em termos de ação como de processo decisório. Uma vez que essas ações contam com a colaboração ativa dos beneficiários, promovem ainda redução no dispêndio de recursos assistenciais para lidar com os problemas visados.

Algumas das propostas supracitadas, como os trabalhos breves e grupais, já possuem tradição, mas mesmo assim são menos utilizadas que os métodos individuais de longa duração. Como quer que seja, conquanto tornem-se mais ágeis e abrangentes, as intervenções podem ser ineficazes se não forem elaboradas a partir de uma base sólida de investigação, que permita verificar sua eficiência. Por exemplo, é comum, na assistência institucional a populações carentes, que se improvisem atendimentos breves ou grupais de eficiência questionável e sem a devida verificação de sua eficácia (Arcaro et al., 1999). Dessa forma, há necessidade de mais estudos que visem avaliar e aperfeiçoar as estratégias mencionadas nas páginas anteriores. Ademais, também há metodologias pouco exploradas que parecem merecer maior atenção. Uma delas consiste nos procedimentos baseados em imagens mentais.

As imagens mentais são aqui referidas consoante sua concepção mais tradicional, relativa aos componentes de fenômenos como sonhos e devaneios. São representações internas de aspecto concreto, sensorial ou perceptivo (Richardson, 1983). O uso de práticas imagéticas tem lugar em diferentes áreas, como a psicologia, a medicina, os esportes e até mesmo a informática. O potencial de tais práticas reside, significativamente, em sua capacidade de provocar sensações, emoções e alterações fisiológicas às vezes bastante acentuadas. Isso faz das imagens instrumentos valiosos para influenciar experiências psíquicas e somáticas (Arcaro, 1997; Samuels \& Samuels, 1975).

$\mathrm{Na}$ psicoterapia, as estratégias imagéticas vêm sendo adotadas desde o desenvolvimento inicial da psicanálise, com o uso de hipnose para evocar imagens de eventos traumáticos. Até hoje a psicanálise, assim como a psicologia analítica de Jung, dá grande relevo à interpretação dos sonhos (Freud, 1900/1972; Jung, 1934/1987). Também na vertente cognitivo-comportamental há vários procedimentos que envolvem imagens mentais, como a dessensibilização sistemática (Wolpe, 1973), a terapia implosiva (Levis, 1993) e a modelação encoberta (Kazdin, 1978). Ainda, diversas abordagens humanistas fazem uso frequente de imagens, e estão entre as principais difusoras de metodologia imagética (Arcaro, 1997).

Já no referente a problemas orgânicos, um exemplo conhecido de prática imagética é o treinamento autógeno de Schultz, que articula relaxamento à mentalização de imagens. Seu uso é frequente em conjunto com estratégias médicas para tratamento de problemas de coluna, cardíacos, gástricos e outros (Arcaro, 1997; Samuels \& Samuels, 1975). Outro emprego de imagens que, segundo Samuels e Samuels (1975) apresenta bons resultados, está no combate ao câncer. Consiste, basicamente, em apresentar gravuras de tumores em remissão e dos próprios raios $\mathrm{X}$ do paciente para orientar a mentalização de imagens, que deve ocorrer no sentido da regressão do mal. Samuels e Samuels (1975) também citam o uso de imagens em anestesia, associado a hipnose, e em oftalmologia, na forma de exercícios oculares imaginários. E há ainda menções de procedimentos imagéticos para lidar com estomatite (Andrews \& Hall, 1990), dor nas costas (Rancour, 1991) e várias outras perturbações orgânicas (Glikin, 2001).

Além disso, as práticas imagéticas atuais estendem-se a outros propósitos, como o aperfeiçoamento nos esportes (Raposo, Costa, \& Carvalhal, 2001). Inclusive na informática há trabalhos com imagens, como o relatado por Browne (1995), referente à utilização delas para controlar computadores, e o de Eisenstadt, Price e Domingue (1992), sobre técnicas de visualização para adquirir familiaridade com programas de informática e para resolver problemas que neles ocorram.

Levando em conta o exposto até o momento, o presente trabalho visou examinar estratégias participativas endereçadas a comunidades carentes e a profissionais que lhes prestam ser- 
viços, dedicando particular atenção, embora não exclusiva, a metodologias imagéticas. Abaixo apresenta-se uma descrição das estratégias implementadas, assim como uma avaliação de tais estratégias com base, principalmente, em depoimentos dos participantes e na produção de trabalhos socioambientais gerada por esses participantes. As intervenções investigadas articularam-se a um empreendimento mais amplo, o projeto "Coletivo Educador da Região Norte da Cidade de São Paulo", conduzido pelo Laboratório de Psicologia Socioambiental e Intervenção (LAPSI), da Universidade de São Paulo (USP), e pelo Instituto Brasileiro de Educação, Ciência e Cultura (IBECC), Comissão de São Paulo, órgão representante da UNESCO no estado de São Paulo. Tal projeto, subvencionado pelo Ministério do Meio Ambiente, objetivava, por meio de educação ambiental, gerar mudanças socioambientais comprometidas com a construção de sociedades sustentáveis e com o desenvolvimento social de populações desprivilegiadas.

Para viabilizar sua proposta, o Coletivo Educador adotou vários procedimentos. $\mathrm{O}$ principal deles foi formar grupos participativos de professores e coordenadores pedagógicos da rede pública de ensino, de líderes comunitários e de agentes comunitários do "Programa Saúde da Família". As intervenções aqui apresentadas abrangeram a maioria das ações empreendidas para a formação e o acompanhamento desses grupos.

\section{Método}

A investigação ora descrita é uma pesquisa empírica aplicada, que pode ser classificada, mais especificamente, como pesquisa de avaliação. Como explicam Selltiz, Wrightsman e Cook (1987), este tipo de pesquisa pode ser realizado para avaliar programas sociais, como no presente caso, o qual se vincula, conforme já mencionado, a um programa de intervenção socioambiental.

\section{Território e População}

O território coberto pelo Coletivo Educador abrangia uma parte da região norte da cidade de São Paulo, os distritos de Anhanguera, Brasilândia, Cachoerinha, Jaraguá, Perus, Mandaqui e
Tremembé, onde vivia uma população de quase um milhão de habitantes. Nesse território havia muitas áreas de risco, ocupadas inadequadamente por assentamentos motivados pela precariedade socioeconômica de sua população. Nessas áreas ocorriam inundações catastróficas e, além de existir grande número de famílias de baixa renda e escolaridade, havia alta densidade de jovens, segmento populacional particularmente sujeito a problemas com desemprego, violência, drogas e sexualidade. Por outro lado, o território era também rico em espaços preservados como o Parque Estadual da Cantareira, o Horto Florestal, o Parque do Jaraguá e o Parque Anhanguera, o maior parque municipal da cidade.

\section{Estratégia Geral de Intervenção}

A estrutura necessária para o Coletivo promover grupos participativos, além de outras estratégias para o aprimoramento das condições de vida nas áreas de risco supracitadas, foi providenciada por meio de parcerias com diversas entidades. Entre estas figuravam as duas diretorias de ensino da Região Norte, da Secretaria Estadual de Educação, o Núcleo de Gestão Ambiental Descentralizada Norte, da Secretaria do Verde e do Meio Ambiente da Prefeitura de São Paulo e a Coordenadoria Municipal de Saúde da Região Norte, da Prefeitura de São Paulo.

A aplicação dos procedimentos compreendidos pela investigação aqui descrita ocorreu em reuniões com professores e coordenadores pedagógicos de escolas estaduais de ensino fundamental e médio e em reuniões com líderes comunitários vinculados a conselhos gestores de saúde do município. Em ambos os casos, o trabalho foi viabilizado por meio de cursos de difusão, que foram promovidos pelo LAPSI/USP, em conjunto com o IBECC/UNESCO, como parte das atividades do Coletivo.

\section{Participantes}

O curso dos professores e coordenadores compreendeu três turmas de participantes, e o dos líderes comunitários uma turma. O montante de pessoas que efetivamente se engajaram nos trabalhos foi de 60,49 no curso de professores e coordenadores e 11 no de líderes comunitários. 
Desse montante, 31 pessoas concluíram os programas propostos. A Tabela 1 apresenta uma ca- racterização geral desses participantes que concluíram os programas.

Tabela 1

Características Gerais dos Participantes que Concluíram os Cursos $(n=31)$

\begin{tabular}{|c|c|c|c|c|}
\hline Curso & Turma & $\begin{array}{l}\text { Participantes } \\
\text { (número) }\end{array}$ & $\begin{array}{l}\text { Sexo } \\
\left(\% \text { e } n^{\circ}\right)\end{array}$ & $\begin{array}{l}\text { Faixa Etária } \\
\left(\% \text { e } n^{\circ}\right)\end{array}$ \\
\hline $\begin{array}{l}\text { Professores e } \\
\text { coordenadores }\end{array}$ & 1 & 6 & $\begin{array}{r}33,3(n=2) \mathrm{M} \\
66,7(n=4) \mathrm{F}\end{array}$ & $\begin{array}{r}0,0(n=0) \text { até } 24 \\
16,7(n=1) 25-34 \\
50,0(n=3) 35-44 \\
33,3(n=2) 45-59 \\
0,0(n=0) 60-69\end{array}$ \\
\hline $\begin{array}{l}\text { Professores e } \\
\text { coordenadores }\end{array}$ & 2 & 8 & $\begin{array}{r}25,0(n=2) \mathrm{M} \\
75,0(n=6) \mathrm{F}\end{array}$ & $\begin{array}{r}0,0(n=0) \text { até } 24 \\
37,5(n=3) 25-34 \\
25,0(n=2) 35-44 \\
25,0(n=2) 45-59 \\
12,5(n=1) 60-69\end{array}$ \\
\hline $\begin{array}{l}\text { Professores e } \\
\text { coordenadores }\end{array}$ & 3 & 7 & $\begin{array}{l}14,3(n=1) \mathrm{M} \\
85,7(n=6) \mathrm{F}\end{array}$ & $\begin{array}{r}0,0(n=0) \text { até } 24 \\
14,3(n=1) 25-34 \\
57,1(n=4) 35-44 \\
28,6(n=2) 45-59 \\
0,0(n=0) 60-69\end{array}$ \\
\hline Líderes comunitários & 1 & 10 & $\begin{array}{r}10,0(n=1) \mathrm{M} \\
90,0(n=9) \mathrm{F}\end{array}$ & $\begin{array}{r}0,0(n=0) \text { até } 24 \\
0,0(n=0) 25-34 \\
10,0(n=1) 35-44 \\
50,0(n=5) 45-59 \\
40,0(n=4) 60-69\end{array}$ \\
\hline
\end{tabular}

Cabe acrescentar que quase todas as desistências (28 dentre 29) ocorreram no curso dos professores e coordenadores, sendo provavelmente provocadas, em maior medida, por dificuldades impostas pela Secretaria da Educação. Entre outros empecilhos colocados pela secretaria, houve a revogação da possibilidade, inicialmente oferecida por ela, de os participantes realizarem o programa em seu horário de trabalho. Isso foi agravado por seguidas convocações para trabalho aos sábados feitas pela secretaria, as quais prejudicaram ainda mais a participação daqueles que optaram pelas turmas que ocorreram nesse dia da semana. Quanto ao curso dos líderes comunitários, houve a desistência de apenas um dos onze alunos, o que constitui uma proporção bastante reduzida e sugere que, de fato, os problemas causados pela Secretaria da Educação tiveram papel relevante nas desistências de alunos vinculados ela.

\section{Instrumentos e Material de Registro}

Questionários Auto-Ppreenchidos. Foram utilizados três questionários. $\mathrm{O}$ primeiro era um instrumento de avaliação geral e levantamento de informações, formulado para avaliar os pro- 
gramas, os projetos realizados pelos alunos e, ainda, obter informações sobre o perfil desses alunos com respeito à realização de trabalhos sociais e ambientais. O segundo destinava-se a avaliar exercícios vivenciais empregados nas aulas. E o terceiro foi elaborado para acompanhamento posterior aos cursos (follow-up). Um detalhamento das questões compreendidas por esses questionários pode ser encontrado nas tabelas de resultados que apresentam frequências e médias das respostas dadas a eles. Essas tabelas incluem, além do cômputo das respostas, também as perguntas que solicitaram tais respostas.

Diários e Notas de Campo. Foram preenchidos tanto em papel, durante sessões de trabalho, como em computador, após essas sessões. Para este último caso, o primeiro autor estruturou um formulário de relatório, que foi preenchido após as reuniões pelos professores dos cursos. Tais relatórios foram digitados em arquivos do Microsoft Excel. A cada turma correspondia um arquivo e a cada reunião uma planilha desse arquivo, sendo a última planilha uma tabela consolidada das planilhas anteriores que, assim, possibilitava uma visão geral dos dados sobre determinada turma.

Roteiro para Trabalho Final dos Alunos. Foi ainda estruturado um roteiro para orientar a redação do relatório final elaborado pelos professores e coordenadores pedagógicos, que descrevia seus trabalhos práticos. O roteiro continha orientações para uso de métodos sistemáticos e assistemáticos de observação, bem como para registro e análise dos eventos que poderiam ser relevantes para caracterizar diferentes facetas dos projetos conduzidos pelos alunos.

Filmadora. Foi usada para filmar os exercícios vivenciais realizados pelos participantes e momentos em que foram solicitadas, desses participantes, informações consideradas cruciais sobre seus projetos.

Computador, Impressora e Papel. Foram utilizados para imprimir roteiros de observação e entrevista, bem como os questionários que foram preenchidos em papel.

\section{Ambiente}

As reuniões com professores e coordenadores foram realizadas em salas de reuniões das diretorias de ensino parceiras do Coletivo. Os encontros com líderes comunitários ocorreram numa sala de aula existente na coordenadoria de saúde da Região Norte.

\section{Procedimentos}

Detalhamento dos Cursos de Difusão. Os cursos diferiram apenas levemente. Em termos de carga horária, no dos professores e coordenadores realizaram-se dez reuniões bissemanais de quatro horas de duração, num total de 40 horas, e no dos líderes comunitários houve nove reuniões bissemanais de quatro horas, num total de 36 horas. Além disso, no programa para professores e coordenadores foi realizada supervisão dos projetos dos alunos via Internet, e foi exigido um trabalho final escrito. Isso não aconteceu no curso dos líderes comunitários, uma vez que os participantes desse programa, majoritariamente, não tinham acesso à Internet, e nem proficiência em redação suficiente para relatarem seus trabalhos por escrito.

Em todos os outros aspectos, os cursos seguiram uma mesma estratégia: consistiram em treinamentos objetivando ensinar a montar e gerir projetos socioambientais participativos. Para tanto, os participantes foram orientados a, além de frequentarem as aulas, conduzirem trabalhos práticos. Os professores dos cursos, nas aulas, expuseram elementos conceituais e metodológicos essenciais para a realização desses trabalhos, supervisionaram os mesmos trabalhos, incentivaram trocas de experiências e utilizaram atividades vivenciais. Estas consistiram, predominantemente, em exercícios imagéticos e de dinâmica de grupo. Tais exercícios visaram propiciar a participação grupal e, no caso das práticas imagéticas, também auxiliar os participantes a enfrentar dificuldades encontradas em seus projetos socioambientais (os procedimentos imagéticos incluíram métodos para planejamento e ensaio de intervenções, bem como para incentivo à criatividade na solução de problemas). A aplicação dos exercícios visou, igualmente, fornecer 
aos participantes ferramentas que eles próprios pudessem utilizar com as pessoas envolvidas em seus projetos, para favorecer a participação e o enfrentamento de problemas.

Além dos procedimentos acima citados, foram empregadas, esporadicamente, algumas outras atividades como exibição de filmes e utilização de recursos plásticos para a expressão de experiências dos participantes. Foi criado também um blog contendo material relacionado a questões socioambientais que poderiam ser do interesse dos frequentadores dos cursos. Os alunos usuários de Internet foram incentivados, inclusive, a colocarem resumos de seus projetos para os cursos no blog, e a maioria o fez. Desse modo, os participantes puderam, ainda, ter notícia de trabalhos de colegas de outras turmas, o que enriqueceu o acervo de informações e de modelos à sua disposição. Finalmente, no encerramento das aulas, foi oferecida, a todos os alunos, uma apostila descrevendo de modo detalhado o plano de atividades dos cursos. Assim, os participantes teriam a possibilidade de, futuramente, reverem a metodologia ensinada, se achassem que ela poderia ser útil para montarem novos projetos.

No curso para professores e coordenadores pedagógicos, já que todos os alunos tinham acesso à Internet, foi-lhes oferecida, conforme exposto acima, supervisão de seus projetos por e-mail, ao par da ocorrida em sala de aula. Cada turma de tal curso foi acompanhada por dois professores. O primeiro autor deste trabalho, principal responsável pelo planejamento de ambos os cursos, foi professor de uma das turmas e coordenador dos demais professores, havendo supervisionado suas atividades.

O segundo curso, oferecido para líderes comunitários, também foi ministrado pelo primeiro autor, com o auxílio de uma professora. Neste caso, como já foi explicado, a maioria dos participantes não tinha acesso à Internet. Por esse motivo, a supervisão de trabalhos foi predominantemente presencial, sendo apenas um participante igualmente supervisionado por e-mail.

\section{Atividades Vivenciais}

Práticas Imagéticas. Foram utilizados exercícios de fantasia dirigida, os quais destinam-se à produção de imagens mentais em estado de vigília. Neles, usualmente, pede-se às pessoas que fechem os olhos, relaxem e imaginem uma viagem ou história narrada pelo aplicador. As imagens que compõem a viagem ou história não são descritas com detalhes, para que os participantes preencham espontaneamente o que não for especificado. Após imaginarem o proposto, as pessoas descrevem sua experiência oralmente, relatam-na por escrito ou valem-se de recursos gráficos, escultura e dramatização para representarem o que imaginaram. O objetivo dos exercícios pode ser diagnóstico, auxiliando a conscientização e a explicitação de problemáticas, o que, em processos grupais, facilita a compreensão mútua entre participantes. Pode também ser de estimular inventividade e mobilização emocional, pois as imagens evocadas muitas vezes são criativas e geram emoções intensas. Dessa forma, é possível usar o procedimento em questão para esclarecer problemas, gerar idéias para resolvê-los e mobilizar o enfrentamento desses problemas (Arcaro, 1997).

Dinâmicas de Grupo. Com vistas à integração grupal, esses exercícios foram empregados para auxiliar os participantes a se conhecerem melhor, aprimorarem sua capacidade de comunicação e aprenderem a realizar tarefas em grupo.

\section{Coleta de Dados}

Aplicação dos Questionários Auto-Preenchidos. Os questionários foram sempre respondidos anonimamente, tendo sido explicada aos respondentes a importância de serem sinceros, para que suas respostas pudessem ser usadas no aperfeiçoamento da metodologia dos cursos. $\mathrm{O}$ primeiro questionário, de avaliação geral e levantamento de informações, foi aplicado na última reunião de cada turma. O segundo, de avaliação de exercícios vivenciais, foi preenchido pelos alunos logo após esses exercícios ocorrerem nas aulas. E o terceiro, para follow-up, foi usado oito meses após a conclusão dos programas. Os três 
questionários, elaborados pelo primeiro autor com colaboração dos demais professores dos cursos, foram aplicados de modo padronizado. Compreenderam predominantemente perguntas de múltipla escolha constituídas, em alguns casos, por escalas de avaliação, além de algumas perguntas abertas. Cabe acrescentar que a análise de resultados contemplada nesse artigo foi predominantemente quantitativa, e por isso não incorporou, por serem qualitativos, a maioria dos dados obtidos com perguntas abertas dos questionários, entrevistas e observações diretas. No entanto, tais dados contribuíram para caracterizar várias situações abarcadas pela pesquisa, e essa caracterização foi fundamental para o planejamento e a condução de muitos dos procedimentos implementados. Ademais, parte dos conteúdos qualitativos foi quantificada e incorporada à análise dos resultados, bem como uma outra pequena parte foi introduzida nessa análise a título de exemplificação.

Entrevistas Individuais ou Grupais. Nas primeiras reuniões dos cursos, entrevistas não estruturadas foram utilizadas pelos professores visando conhecer os alunos e que eles conhecessem uns aos outros. Já em reuniões posteriores, quando os alunos já haviam começado a realizar seus trabalhos práticos, era realizada supervisão desses trabalhos, o que exigia que os participantes os descrevessem. Dessa maneira, em vários momentos, tal supervisão também incluiu entrevistas não estruturadas visando obter informações sobre os projetos que os alunos realizavam. Em algumas ocasiões, segmentos dessas entrevistas considerados mais importantes foram redigidos nas próprias reuniões. $\mathrm{O}$ primeiro autor ainda estruturou, conforme dito acima, um formulário de relatório, que foi preenchido pelos professores dos cursos, em arquivos do Microsoft Excel, após cada reunião. Nos relatórios anotaram-se as informações consideradas relevantes que foram colhidas nas entrevistas ou por meio de observação direta feita pelos professores durante as aulas. Além disso, nos encontros das turmas de que o primeiro autor foi professor, como também já foi mencionado, filmaram-se os exercícios vivenciais e ocasiões em que se solicitaram aos alunos informações tidas como cruciais no referente a seus projetos. Essas filmagens constituíram mais uma forma de registro das entrevistas.

Observações Diretas. Compreenderam aspectos da conduta dos participantes como frequência às reuniões e características de sua participação nelas. Foram sistemáticas no referente à frequência dos alunos, e assistemáticas no que tocou à qualidade da participação destes nos encontros. As assistemáticas, assim como as entrevistas, foram anotadas nos relatórios das reuniões e, por vezes, no próprio decorrer dos encontros, conforme já exposto. Algumas observações também foram filmadas, principalmente as referentes à execução de exercícios vivenciais, visando posteriormente avaliar a aplicação desses exercícios.

Registros Realizados pelos Alunos. Tais registros ocorreram na forma dos relatórios finais redigidos por todos os professores e coordenadores pedagógicos, que descreviam seus trabalhos práticos e eram parte das solicitações feitas pelo seu curso. Os relatórios foram todos compostos de acordo com o padrão apresentado no roteiro para trabalho final dos alunos explicado acima.

Avaliação Final. A última reunião dos cursos foi de avaliação dos resultados destes. Iniciou-se pelo preenchimento do questionário de avaliação geral e levantamento de informações, para que a discussão sobre os resultados não pudesse sugestionar as respostas dadas a ele. Realizou-se, em seguida, um exercício de fantasia dirigida para avaliação grupal que visou propiciar a discussão posterior, esta última orientada por metodologia de grupo focal pautada por um roteiro utilizado em todas as turmas.

Acompanhamento Posterior aos Cursos - Follow-Up. Consoante o exposto acima, utilizou-se um questionário de acompanhamento, aplicado em agosto de 2009, oito meses após encerradas as intervenções. Tal questionário foi enviado por e-mail aos ex-alunos do programa para professores e coordenadores pedagógicos. O follow-up permitiu colher alguns dados para verificar se as impressões dos ex-participantes a respeito dos cursos haviam se mantido após o término destes, e averiguar se as atividades ligadas a projetos socioambientais dos mesmos 
ex-participantes haviam prosseguido. Quanto aos ex-alunos do programa para líderes comunitários, como sua maioria não possuía endereço eletrônico, o acompanhamento não foi realizado com eles. Apesar disso, um dos poucos ex-participantes do curso em questão que tinha acesso à Internet continuou, espontaneamente, por vários meses, trocando e-mails com os ex-coordenadores do programa e informando-os sobre as atividades que continuara a realizar. Dessa forma, foi possível saber que, ao menos em um caso desse curso, os resultados das intervenções se mantiveram.

\section{Cuidados Éticos}

O projeto desta investigação foi aprovado pelo Comitê de Ética em Pesquisa com Seres Humanos do Instituto de Psicologia da Universidade de São Paulo. Os alunos dos cursos, antes de iniciarem sua participação, foram informados dos objetivos e das estratégias que o projeto envolvia. Foram também informados de que essa participação poderia ser interrompida, a seu critério, em qualquer momento. Além disso, foi firmado compromisso de se manter em sigilo a identidade individual dos participantes, e acrescentou-se que quaisquer dúvidas que surgissem no decorrer das atividades realizadas poderiam ser esclarecidas nas reuniões dos cursos, por $e$ -mail ou por telefone. Essas notificações foram redigidas em cartas de esclarecimento entregues aos alunos no início dos trabalhos, ocasião em que os professores se prestaram a oferecer quaisquer outros esclarecimentos que se julgassem necessários. Na mesma ocasião os participantes também assinaram o termo de consentimento livre e esclarecido.

\section{Análise de Dados}

$\mathrm{O}$ volume de informações produzido com a utilização dos diversos instrumentos de coleta de dados usados nesta pesquisa foi bastante grande, não cabendo no escopo deste artigo apresentá-lo e analisá-lo em sua totalidade. Dessa forma, para a análise de resultados exposta a seguir, foram utilizados predominantemente dados quantitativos, por serem considerados mais fidedignos em termos de avaliação, e também por possibilitarem um panorama global dos resultados obtidos. Mais especificamente, os resultados abaixo apresentam uma análise estatística descritiva dos dados quantitativos obtidos por meio dos três questionários auto-preenchidos empregados nesta investigação, cujas questões de múltipla escolha foram forjadas com vistas a esse tipo de análise. A apresentação dos resultados inclui, ainda, uma caracterização sintética dos projetos realizados pelos alunos dos cursos, assim como do comportamento de tais alunos. Tal caracterização, extraída da observação direta dos participantes, de depoimentos apresentados por eles e dos trabalhos redigidos pelos professores e coordenadores, foi incluída no texto para permitir ao leitor uma visão global, embora sucinta, da produção e do comportamento das pessoas que participaram deste estudo ${ }^{2}$.

\section{Resultados e Discussão}

Diversos indicadores demonstraram o sucesso dos cursos que constituíram as intervenções implementadas nesta pesquisa. Isso pode ser observado, em primeiro lugar, na Tabela 2, que apresenta os resultados das principais questões quantitativas do questionário geral de avaliação e levantamento de informações. Talvez a constatação mais importante que essa tabela permita seja a de que, enquanto $44,8 \%(n=13)$ dos alunos disseram haver participado de projetos socioambientais antes dos cursos, e 34,5\% ( $n$ =10) disseram também haver montado ou coordenado algum dos projetos de que participaram, $89,7 \%(n=26)$ idealizaram e efetivaram os trabalhos solicitados pelos programas. Cabe ressaltar que a concretização desses trabalhos não apenas foi indicada no questionário, mas também verificada mediante documentação e depoimentos detalhados que seus realizadores apresentaram, o que evidencia a fidedignidade dessa

2 O primeiro autor se coloca à disposição para contato, pelos meios indicados no início deste artigo, com leitores que desejarem maiores informações sobre os resultados e as características mais específicas da investigação aqui apresentada. 
constatação. Ademais, se houve motivação dos alunos para falsearem depoimentos quanto a trabalhos que fizeram antes dos cursos, esta, provavelmente, foi majoritariamente no sentido de se valorizarem dizendo ter efetuado mais trabalhos do que realmente empreenderam. E isso tornaria ainda mais expressivo o aumento de sua participação em projetos socioambientais propiciado pelas intervenções implementadas. É pertinente acrescentar que esse aumento foi suficientemente vultoso para descartar a possibilidade de haver ocorrido espontaneamente no curto espaço de tempo dos cursos. Essa possibilidade é tanto mais implausível na medida em que a majoração verificada envolveu o engajamento de significativa quantidade de pessoas que nunca haviam participado de projetos sociais ou ambientais, e não apenas um incremento da frequência de trabalhos que já eram feitos pelas pessoas.

Fica assim demonstrado, de maneira clara, que as intervenções cumpriram uma de suas metas mais importantes, qual seja a de fomentar a realização de projetos socioambientais. A esse respeito deve-se ainda esclarecer que, conquanto os cursos solicitassem a execução desses projetos pelos alunos, os professores foram tolerantes e compreensivos com aqueles que afirmaram desejar acompanhar os programas, mas não terem possibilidade, na ocasião, de realizarem o trabalho prático solicitado. Sendo assim, a realização de projetos socioambientais gerada pelas intervenções revestiu-se de motivação basicamente positiva, não tendo sido estimulada por exigências rígidas ou ameaça ao engajamento dos alunos nos cursos. E o caráter predominantemente voluntário dessa realização aumenta as chances de ela se ter mantido após o término dos programas. E mais uma indicação do sucesso das intervenções apresentada pela Tabela 2 foi a de que os alunos avaliaram de maneira positiva os cursos como um todo, atribuindo-lhes uma nota média de 8,9 (variação de 0 a 10), e a atuação dos professores ("coordenadores", na Tabela 2) de tais cursos, atribuindo-lhe uma nota média de 9,3. Esses resultados, em termos de produção e avaliação dos alunos, parecem evidenciar a contribuição deste estudo para a área de desenvolvimento social, particularmente no que toca ao acervo de metodologias participativas utilizadas nessa área (e. g. Costa, 1997; Esteves, 2004; Konuma, 2005; Velásquez, 2002).

Outro indício importante foi o de que os tipos de atividades realizadas nos programas também foram avaliados positivamente, recebendo notas médias que variaram entre 8,8 (apresentações feitas pelos alunos) e 9,7 (apresentações feitas pelos coordenadores). Uma vez que as respostas aos dois questionários aplicados foram anônimas, não há motivo sério para supor que a atribuição dessas notas objetivasse agradar os professores, mesmo porque a sinceridade das respostas foi, conforme já explicado, explicitamente incentivada.

Ainda a esse respeito cabe destacar que as práticas imagéticas ("exercícios de imaginação", na Tabela 2), cuja avaliação constituiu um dos principais objetivos deste estudo, conquistaram boa acolhida por parte dos alunos. A média das notas recebidas por essas práticas foi de 9,3 e, além disso, 34,5\% $(n=10)$ dos participantes afirmaram que já haviam começado a utilizá-las em seus trabalhos. Apesar de esses procedimentos não serem tão fáceis de aplicar e de serem bem menos difundidos que as dinâmicas de grupo, a nota média a eles atribuída foi quase idêntica à recebida pelas dinâmicas $(9,4)$, e foram empregados nos projetos dos alunos com frequência significativa, embora não tão alta quanto a das dinâmicas, usadas por $51,7 \%(n=15)$ dos participantes. Pode-se, assim, concluir que o emprego de tais procedimentos preencheu as expectativas iniciais desta pesquisa. Isso reveste-se de importância maior tendo em vista que, até o final das intervenções aqui descritas, não foi encontrada a utilização de práticas imagéticas, no Brasil ou no exterior, associada a estratégias de desenvolvimento social, fossem essas estratégias participativas ou não. Diga-se, inclusive, que a investigação sobre tais práticas especificamente no Brasil restringe-se, quase inteiramente, a procedimentos em âmbito individual com propósitos terapêuticos (e. g. Gallbach, 1989; Lima, 1990). Embora um único trabalho nacional encontrado, o de Arcaro (1997), tenha empregado essas práticas em contexto grupal, os grupos com que esse autor trabalhou foram também de 
teor terapêutico, e não voltados para o desenvolvimento social.

Outro indício do êxito das intervenções foi o de que, entre os alunos que realizaram projetos para os cursos, $53,8 \%(n=14)$ afirmaram haver obtido bastante resultado e que iriam obter mais ainda, 19,2\% $(n=5)$ disseram haver tido alguns resultados e que iriam ter ainda mais, $11,5 \%(n=$ 3) relataram não haver obtido todos os resultados esperados mas que tiveram resultados positivos, e 3,8\% $(n=1)$ afirmaram ainda não haver obtido, mas que iriam obter bastante resultado. Nenhum participante afirmou que seu trabalho não apresentara nem iria apresentar bons resultados.

Além do mais, 93,1\% $(n=27)$ dos alunos disseram, ao final dos programas, acreditar estarem capacitados para montar projetos participativos, e $82,8 \%(n=24)$ deles afirmaram que os cursos os ajudaram bastante a aprenderem a montar esse tipo de projeto, ou a aprimorarem sua capacidade nesse sentido. Estes são indícios não só do papel importante atribuído aos cursos pelos participantes, mas de que estes terminaram os programas sentindo-se aptos a realizarem trabalhos socioambientais. E além de se julgarem aptos, 93,1\% $(n=27)$ deles ainda disseram pretender, futuramente, participar de trabalhos desse gênero, e em igual proporção disseram ter o intento, inclusive, de montar por si próprios projetos do tipo mencionado. Dessa forma, as respostas dos alunos revelaram motivação em continuarem a realizar trabalhos socioambientais, o que veio ao encontro de mais uma grande meta das intervenções, a de não apenas promover participação em tal gênero de trabalho, mas uma participação permanente e auto-sustentável.

Tabela 2

Porcentagem ou Média dos Itens de Avaliação Quantitativa dos Programas de Intervenção $\left(n=29^{*}\right)$

\begin{tabular}{lrr}
\hline \multicolumn{1}{c}{ Questão / alternativa } & $\%$ / Média \\
\hline Você já participou de algum projeto social ou ambiental antes de fazer este curso? & Sim & $44,8(n=13)$ \\
& Não & $51,7(n=15)$ \\
Você já montou/coordenou algum projeto social/ambiental antes de fazer o curso? & Sim $34,5(n=10)$ \\
& Não $\quad 65,5(n=19)$ \\
Você montou ou está montando algum projeto social ou ambiental para este curso? & Sim $89,7(n=26)$ \\
& Não & $10,3(n=3)$
\end{tabular}

Responda só se você montou, ou aproveitou, algum trabalho como projeto prático para o curso:

O projeto já teve bastante resultado positivo e terá mais ainda

$$
\begin{array}{r}
53,8(n=14) \\
0,0(n=0) \\
19,2(n=5) \\
11,5(n=3) \\
3,8(n=1) \\
0,0(n=0) \\
0,0(n=0)
\end{array}
$$
O projeto já teve bastante resultado positivo e não terá mais do que isso

O projeto já teve alguns resultados positivos e terá mais ainda O projeto não teve todos os resultados esperados, mas teve resultados positivos

O projeto ainda não teve, mas terá bastante resultado positivo O projeto ainda não teve, mas terá alguns resultados positivos O projeto ainda não teve e não terá resultados positivos

Você acredita estar capacitado(a) para montar e coordenar que tipo(s) de projetos sociais ou ambientais? (pode marcar mais de uma alternativa) Projetos participativos $93,1(n=27)$ Projetos não participativos $20,7(n=6)$

Nenhum tipo de projeto $0,0(n=0)$ 
Este curso ensinou você a montar projetos participativos, ou melhorou sua capacidade de montar esse tipo de projeto?

$$
\begin{array}{rr}
\text { Bastante } & 82,8(n=24) \\
\text { Um pouco } & 17,2(n=5) \\
\text { Não } & 0,0(n=0) \\
\text { Sim } & 93,1(n=27) \\
\text { Talvez } & 6,9(n=2) \\
\text { Não } & 0,0(n=0)
\end{array}
$$

Você pretende, no futuro, participar de projetos sociais ou ambientais?

Você pretende, no futuro, montar projetos sociais/ambientais? (pode marcar mais de uma)

Sim, projetos participativos

93,1 $(n=27)$

Sim, projetos não participativos

$20,7(n=6)$

Não

$0,0(n=0)$

Marque as atividades usadas neste curso que você começou a usar após o início do curso em grupos coordenados por você próprio(a) (pode marcar mais de uma ou nenhuma):

$$
\begin{array}{rr}
\text { Exercícios de imaginação } & 34,5(n=10) \\
\text { Exercícios de dinâmica de grupo } & 51,7(n=15) \\
\text { Discussões durante as reuniões } & 75,9(n=22) \\
\text { Supervisões de trabalhos práticos } & 44,8(n=13) \\
\text { Apresentações feitas pelos coordenadores } & 27,6(n=8) \\
\text { Apresentações feitas pelos demais participantes } & 51,7(n=15)
\end{array}
$$

Marque com um $\mathrm{X}$ uma nota de 0 a 10 para este curso como um todo:

$M=8,9$

Marque uma nota para o trabalho dos coordenadores neste curso:

$M=9,3$

Marque uma nota para a participação dos alunos neste curso:

$M=8,0$

Marque uma nota para cada um dos tipos de atividade deste curso:

Exercícios de imaginação

$M=9,3$

Exercícios de dinâmica de grupo

$M=9,4$

Discussões durante as reuniões

$M=9,1$

Supervisões de trabalhos práticos

$M=9,3$

Apresentações feitas pelos coordenadores

$M=9,7$

Apresentações feitas pelos demais participantes (alunos)

$M=8,8$

Nota. *Embora 31 participantes tenham concluído satisfatoriamente as exigências dos cursos, dois deles não compareceram à ultima aula, de modo que 29 pessoas responderam à avaliação apresentada na tabela. Além disso, o número de respostas variou pois havia questões que admitiam mais de uma resposta e questões que não foram respondidas por todos os respondentes.

Quanto aos exercícios vivenciais específicos que foram utilizados, as perguntas do questionário de avaliação dessas atividades que solicitavam respostas quantitativas (notas de zero a dez para certos aspectos dos exercícios), bem como seus resultados médios em cada exercício, são apresentados na Tabela 3. Tais resultados mostram que as avaliações dos diferentes aspectos dos exercícios foram positivas. As médias das notas conferidas a esses aspectos oscilaram entre 7,7 e 10,0, e dois terços delas atingiram 9,0 ou mais pontos. Desse modo, pode-se afirmar, 
novamente neste caso, que os indicadores obtidos denotaram a eficácia das intervenções, visto que todos os exercícios compreendidos por elas foram considerados úteis pelos participantes dos programas.

Tabela 3

Exercícios Aplicados, Questões Quantitativas do Questionário de Avaliação de Exercícios e Médias das Notas (0 a 10) Atribuídas a essas Questões

Exercício (número de respondentes) / Questão

Média

Fantasia dirigida sobre visão ecossistêmica $\left(n=21^{*}\right)$

Dê uma nota de 0 a 10 para o exercício e explique o porquê da nota:

Dê uma nota de 0 a 10 para o modo como o exercício foi aplicado e explique o porquê da nota:

Dê uma nota de 0 a 10 para sua participação no exercício e explique o porquê da nota:

Feira mágica $(n=15)$

Dê uma nota de 0 a 10 para o exercício e explique o porquê da nota:

Dê uma nota de 0 a 10 para o modo como o exercício foi aplicado e explique o porquê da nota:

Dê uma nota de 0 a 10 para sua participação no exercício e explique o porquê da nota:

Nome associado à história do nome e a alguma coisa de que a pessoa goste $(n=14)$

Dê uma nota de 0 a 10 para o exercício e explique o porquê da nota:

Dê uma nota de 0 a 10 para o modo como o exercício foi aplicado e explique o porquê da nota:

Dê uma nota de 0 a 10 para sua participação no exercício e explique o porquê da nota:

Festa a fantasia $(n=13)$

Dê uma nota de 0 a 10 para o exercício e explique o porquê da nota:

Dê uma nota de 0 a 10 para o modo como o exercício foi aplicado e explique o porquê da nota:

Dê uma nota de 0 a 10 para sua participação no exercício e explique o porquê da nota:

Fantasia dirigida para mapeamento e solução de problemas $(n=14)$

Dê uma nota de 0 a 10 para o exercício e explique o porquê da nota:

Dê uma nota de 0 a 10 para o modo como o exercício foi aplicado e explique o porquê da nota:

Dê uma nota de 0 a 10 para sua participação no exercício e explique o porquê da nota:

Ensaio comportamental encoberto $(n=4)$

Dê uma nota de 0 a 10 para o exercício e explique o porquê da nota:

Dê uma nota de 0 a 10 para o modo como o exercício foi aplicado e explique o porquê da nota:

Dê uma nota de 0 a 10 para sua participação no exercício e explique o porquê da nota:

Fantasia dirigida sobre grupo que ajuda a resolver problemas $(n=13)$

Dê uma nota de 0 a 10 para o exercício e explique o porquê da nota:

Dê uma nota de 0 a 10 para o modo como o exercício foi aplicado e explique o porquê da nota:

Dê uma nota de 0 a 10 para sua participação no exercício e explique o porquê da nota:

Nota. ${ }^{*}$ O número de participantes de cada exercício foi variável porque, como o comportamento das turmas diferiu de uma para outra e a proposta dos cursos foi se amoldarem a esse comportamento, houve variação na forma de aplicação da metodologia utilizada. Tal metodologia, entretanto, foi seguida, em termos essenciais, em todas as turmas, apesar de em algumas terem sido aplicados mais exercícios que em outras e de, em certos casos, não ter parecido oportuno interromper o fluxo de mobilização despertado pelos exercícios para aplicar o questionário de avaliação. 
À semelhança das respostas às questões quantitativas dos questionários, expostas nas Tabelas 2 e 3, também as oferecidas às suas questões abertas indicaram o sucesso das intervenções. Apenas a título de exemplificação, serão colocadas abaixo algumas dessas respostas. Elas serão identificadas somente em termos do curso de que o respondente participou, já que, por motivos explicados acima, os questionários foram sempre respondidos anonimamente.

Quanto ao questionário de avaliação geral e levantamento de informações, podem-se encontrar exemplos ilustrativos em algumas respostas dadas à questão "O que foi bom para você e o que não foi bom para você neste curso":

"Tudo o que aprendi foi bom para mim, desde o começo quando aprendi a mapear situações até a confecção do trabalho final. As discussões, os debates, as opiniões, as conversas, tudo acrescentou bastante" (Curso de professores e coordenadores, turma 1).

O que en aproveitei durante o curso foram as discussões e atividades desenvolvidas me fizeram lançar um olhar diferente para buscar sempre novos caminhos na solução de conflitos ou situações desafiadoras e perceber que através de uma gestão participativa pode-se encontrar soluções e cada um pode ser parte e contribuir para a sua realização. (Curso de professores e coordenadores, turma 2)

"Foi ótimo, os pontos positivos foram maravilhosos, os pontos negativos não houve" (Curso de professores e coordenadores, turma 3 ).

"Valorizar o ser humano e o que ele é capaz, ter e concluir seu objetivo. Trocar experiências. Entrar em alfa!!!" (Curso de líderes comunitários).

Já com relação ao questionário de avaliação de exercícios vivenciais, podem-se citar algumas respostas oferecidas para a questão "Sem pensar muito, diga qual foi, para você, o significado do que sentiu e imaginou no exercício":

"Me senti angustiada no primeiro momento mas com o desenrolar da dinâmica me senti livre e solta voando... voando sem querer voltar" (Curso de professores e coordenadores, turma 1).
"Cuidado! Estão cuidando de mim... Preciso continuar cuidando dos meus!" (Curso de professores e coordenadores, turma 2).

"Integração" (Curso de professores e coordenadores, turma 3).

"Me senti fazendo parte deste mundo, e ver quanta beleza existe" (Curso de líderes comunitários).

Outra demonstração do êxito dos programas pode ser encontrada no exame dos trabalhos práticos que grande parte dos alunos realizou. Alguns desses projetos foram bem amplos, superando significativamente as solicitações feitas aos participantes, e envolvendo considerável dispêndio de tempo e esforço, o que é mais um indício de elevado nível de motivação. A Tabela 4 apresenta uma breve caracterização dos projetos e de seus resultados finais ou parciais (vários trabalhos continuaram após os cursos, uma vez que a proposta destes era de tais empreendimentos se perpetuarem, ou serem sucedidos por novos projetos dos ex-participantes). Como se pode perceber na tabela em questão, a grande maioria dos trabalhos mostrou bons resultados ou, no mínimo, perspectivas promissoras.

Além da realização significativa de projetos socioambientais por parte dos alunos, outro indicador comportamental relevante do sucesso das intervenções refere-se à frequência às reuniões dos participantes que concluíram os programas. Sua média geral, de $90,79 \%$, foi plenamente satisfatória para os propósitos das intervenções, e sugeriu uma motivação igualmente satisfatória de tais participantes.

É ainda importante acrescentar que as trocas de experiências entre os alunos dos programas também se revelaram bastante produtivas. As informações e idéias que uns receberam dos outros constituíram auxílio importante para o planejamento e a execução dos projetos realizados. Ademais, conjuntos de duas a quatro pessoas se agruparam para a realização de vários dos trabalhos, o que proporcionou maior consolidação de uma atitude de cooperação entre os alunos. Tal fato constituiu indicador comportamental evidente do nível de participação alcançado nos cursos. 
Tabela 4

Projetos Realizados nos Cursos, suas Principais Características e seus Principais Resultados

\begin{tabular}{ll}
\hline \multicolumn{1}{c}{ Projeto } & \multicolumn{1}{c}{ Características } \\
\hline $\begin{array}{l}\text { Prevenção } \\
\text { da dengue }\end{array}$ & $\begin{array}{l}\text { Profissionais da escola e de uma Unidade } \\
\text { Básica de Saúde (UBS) ofereceram } \\
\text { orientação aos alunos e suas famílias }\end{array}$ \\
$\begin{array}{l}\text { Reciclagem } \\
\text { de lixo em } \\
\text { área carente }\end{array}$ & $\begin{array}{l}\text { Divulgação à comunidade e articulação com } \\
\text { sua associação de moradores para coleta do } \\
\text { lixo que comprometia a qualidade ambiental } \\
\text { e comercialização do material reciclável }\end{array}$
\end{tabular}

Alunos promovem melhoria da escola

Prevenção de acidentes na escola

A família na escola e na comunidade

Projeto meio ambiente

O grafite melhorando o meio ambiente

Para onde vão os lixos

Responsabilidade socioambiental na infância

Projeto eco 2008

Cuidar é preciso

Solo, água e ar

Reciclar para não desperdiçar

Orientação nutricional
Levantamento de sugestões dos alunos para melhoria da escola e implementação, por eles próprios e pela escola, dessas sugestões

Os alunos sugeriram medidas de segurança para locais com risco de acidentes, sendo acolhidas as sugestões viáveis

Familiares de alunos participaram de reuniões para organizarem ações que suprissem diversas de suas necessidades

Baseado em iniciativa de empresa privada e pautado pelos princípios de senso de utilização, ordem, limpeza, saúde e autodisciplina

A partir de pesquisa sobre a temática ambiental, alunos idealizaram e produziram grafites em várias paredes da escola

A escola toda se articulou visando reeducação ambiental e participação, e obteve-se consenso quanto às ações a serem adotadas

Apresentação de problemas ambientais para promover a discussão e a mobilização das crianças para resolvê-los

Construção de lixeiras pelos alunos e palestras sobre responsabilidade ambiental e reutilização do que é jogado fora

Alunos analisaram a produção de lixo na escola e discutiram como minimizá-la

Os alunos elaboraram um jogo com perguntas sobre solo, água e ar, que foi aplicado na escola e no curso de difusão

Alunos de $1^{\mathrm{a}}$ a $4^{\mathrm{a}}$ séries construíram brinquedos com material reutilizável, e os utilizaram em gincanas e atividades motoras

Palestras sobre nutrição, oferecidas numa UBS, para promoção de saúde e diminuição do descarte de alimentos aproveitáveis
Bem sucedido, ia-se propor sua expansão para outras escolas à subprefeitura local

Ao término do curso houvera a divulgação e começara-se a organizar, por meio da associação de moradores, uma cooperativa para comercializar o material reciclável

Ao final do curso a implementação das sugestões estava em fase de planejamento, sendo apoiada pela direção da escola

As sugestões começaram a ser implementadas antes do término do curso, contando com o patrocínio da direção da escola

Os encontros começaram durante o curso e continuaram, após seu término, até a autora suspendê-los por razões particulares

Concluído para o ano em que ocorreu o curso e com perspectiva de continuidade com apoio da empresa parceira

Os grafites foram realizados, mas posteriormente foram alvo de pichação.

Houve apresentações e uma feira cultural, e planejava-se uma peça de teatro em que o projeto seria exibido pelos alunos

Os resultados foram comprovados pela verificação do aumento do lixo descartado em lixeiras para materiais recicláveis

Planejou-se pesar o lixo descartado antes e depois das ações adotadas. Apenas a primeira pesagem ocorreu durante o curso

As idéias desses alunos foram implementadas e divulgadas na escola

A autora coordenou um primeiro grupo de alunos que deveria, depois, coordenar alunos de séries menos avançadas

As atividades propiciaram cooperação, conscientização ambiental e organização, e pretendia-se a continuidade do trabalho

$\mathrm{O}$ projeto foi bem aceito pelos participantes, o que permitiu mobilizá-los para organizarem novos ciclos de palestras 
Eliminação

de lixo que

sujava calçadas

Atenção a crianças em fila de espera

\section{Artesanato e qualidade de vida do idoso}

Sexualidade, drogas e cidadania
Orientação dos moradores que descartavam impropriamente o lixo e criação de estrutura adequada para depositar o mesmo

Obteve-se verba para construção de uma sala de entretenimento para crianças que ficavam em fila de espera numa UBS

Organizaram-se grupos de idosos para produzirem artesanato e vendê-lo numa feira do gênero nos fins de semana

Montagem de grupos de adolescentes em UBS para trabalhar os temas propostos por meio de educação participativa
As intervenções apresentaram progressos durante o curso e pretendia-se dar seguimento às ações implementadas

Ao final do curso a sala fora construída, anexa ao prédio da UBS, e estava sendo aparelhada para o trabalho com as crianças

Ao fim do curso, o treinamento dos idosos fora estruturado e fora autorizada a venda do produto na feira selecionada

Ao término do curso o trabalho fora planejado e autorizado pela UBS para ser realizado a partir do início do ano seguinte
Além das avaliações já apresentadas realizou-se, conforme acima citado, um acompanhamento, posterior às intervenções, dos ex-participantes do programa para professores e coordenadores pedagógicos. Quatro das 21 pessoas que concluíram esse programa responderam, por e-mail, ao questionário que lhes foi enviado, sendo que um dos questionários não pôde ser aproveitado por erro de preenchimento, ou de envio, por parte de sua respondente (o questionário foi recebido de volta em branco). Cabe aqui lembrar que, embora esse procedimento não tenha abrangido, por razões já expostas, os ex-alunos do curso para líderes comunitários, um deles continuou espontaneamente a se comunicar por e-mail com os ex-coordenadores de seu programa, o que permitiu o acompanhamento também desse ex-aluno. E convém esclarecer que o pequeno retorno obtido pelo procedimento ora descrito é normal e fora esperado, já que questionários enviados por correspondência não costumam ser preenchidos por mais de $20 \%$ ou $25 \%$ daqueles para quem são encaminhados (Mattar, 2000). Tendo isso em mente, o acompanhamento presentemente descrito foi planejado para ser apenas um instrumento de coleta de dados secundário, que permitisse a obtenção de algumas notícias sobre eventuais efeitos prolongados das intervenções realizadas.

Uma vez que o número de casos acompanhados não parece justificar uma tabulação quantitativa dos dados, será aqui apresentado apenas um resumo dos depoimentos obtidos. Re- lativamente aos ex-participantes dos programas para professores e coordenadores, uma das ex-alunas que respondeu ao questionário informou que seu trabalho continuava à época do acompanhamento, e as outras duas declararam que seus projetos haviam continuado por algum tempo, mas terminaram. Além disso, dois dos trabalhos foram considerados como muito bem-sucedidos por suas autoras, e em um caso a autora julgou ter obtido resultados positivos, embora não todos os que esperava.

Duas das respondentes também disseram que, após o encerramento dos cursos, montaram e continuavam a conduzir novos trabalhos socioambientais (um de reciclagem de sucata para produção de material didático e outro de conscientização dos membros da comunidade que frequentava a escola sobre a importância de conservar as dependências da instituição). Ambas afirmaram que haviam empregado, e continuavam utilizando, nesses novos trabalhos, coisas que aprenderam nos cursos, uma delas citando, especificamente, exercícios imagéticos. A terceira respondente relatou não ter participado de nenhum outro trabalho, mas que pretendia montar novos projetos no futuro, e que havia utilizado com sucesso um exercício imagético para lidar com problemas de relacionamento de uma classe muito difícil existente em sua escola.

As três respondentes ainda alegaram que os cursos as auxiliaram de diversas formas: a aprimorar sua capacidade de montar e coordenar projetos participativos, a compreender melhor 
a questão ambiental, a entender a necessidade de sensibilizar as pessoas para o fato de que o meio onde vivem também é "meio ambiente", e a aprender estratégias de mobilização grupal. Como sugestões para novos projetos do LAPSI/USP e do IBECC/UNESCO, as respondentes mencionaram: a continuidade dos cursos; sua ampliação para um programa maior e mais longo, oficializado pelo Ministério da Educação (MEC); divulgação prévia mais abrangente e detalhada de novos cursos; e prioridade para professores do ensino fundamental, preparando-os para conscientizarem as crianças desde cedo sobre questões socioambientais.

Por fim, no que toca ao ex-aluno do programa para lideres comunitários que continuou a se comunicar com os ex-professores de seu curso, as informações por ele oferecidas sobre solicitações de continuidade de seu projeto feitas pelos participantes revelaram a manutenção da permanência e do sucesso desse projeto.

\section{Considerações Finais}

Como foi explicado anteriormente, o estudo aqui apresentado consiste numa pesquisa de avaliação. Segundo Selltiz et al. (1987), a pesquisa de avaliação adota, usualmente, delineamentos descritivos, como nesta investigação, quase-experimentais e experimentais. Difere, entretanto, da pesquisa básica, por incluir propósitos práticos, objetivando descobertas que sejam de utilização e implementação mais imediata. No caso da pesquisa de avaliação vinculada a programas sociais, apesar de ela usar procedimentos de pesquisa básica, por ser realizada para avaliar programas em curso, ela é planejada com um espaço de tempo menor que a pesquisa básica. As decisões sobre projetos como o Coletivo Educador, que foi subvencionado pelo Ministério do Meio Ambiente, precisam ser tomadas de maneira relativamente rápida, porque a distribuição de verbas para tais projetos frequentemente se baseia em resultados demonstráveis a curto prazo. Em vista disso, na pesquisa de avaliação de programas sociais, os programas têm prioridade sobre as investigações realizadas para avaliá-los, de modo que esse tipo de pesquisa vê suas possi- bilidades de execução limitadas pelas necessidades desses programas. Ademais, os procedimentos investigados por essas pesquisas ocorrem em ambiente natural e complexo, e sendo assim não costuma ser possível controlar parcela significativa das variáveis presentes na situação abordada. Devido a tais limitações, a investigação aqui exposta recorreu, com bastante frequência, a depoimentos e, apenas em momentos mais raros, a verificações objetivas. Além disso, não foi possível fazer uma avaliação anterior às intervenções que pudesse ser confrontada com a avaliação final, e seria totalmente inviável a utilização de algum tipo de grupo de controle. Dessa forma, os resultados obtidos são apenas indicativos, e não conclusivos. Apesar disso, esta pesquisa parece haver obtido informações que, em alguns casos, permitem afirmar de maneira convincente que as intervenções implementadas foram bem sucedidas. Cabe ao leitor julgar se estamos corretos ou não a esse respeito.

Quanto aos indicadores utilizados, eles mostram primeiramente que as intervenções, estruturadas na forma dos cursos acima descritos e analisados, foram globalmente bem avaliadas pelos participantes, e ainda propiciaram a elaboração de vários trabalhos socioambientais. Isso parece demonstrar, de maneira razoavelmente inequívoca, que a metodologia participativa utilizada se revelou bem-sucedida, podendo ser eventualmente adaptada a outros projetos participativos voltados para o desenvolvimento social. Some-se a isso que as atividades específicas adotadas nos cursos, como os exercícios imagéticos e as dinâmicas de grupo, também foram valorizadas positivamente pelos participantes. No que toca especificamente aos exercícios imagéticos, uma das preocupações centrais desta investigação, eles não só foram bem avaliados, como utilizados em projetos de alunos durante e após os cursos. A aplicação desses exercícios ultrapassou, inclusive, os limites da ação socioambiental, concorrendo ainda para resolver problemas de relacionamento em sala de aula. Desse modo, também é plausível afirmar que as práticas imagéticas podem trazer contribuição importante para as intervenções de cunho social e socioambiental. 
Por fim, também é bom lembrar que, assim como o presente trabalho, já vêm sendo realizados outros, em âmbito nacional, implementando e investigando novas estratégias que possibilitem maior agilidade e abrangência ao atendimento a populações carentes. Entretanto, conforma já dito, esses trabalhos ainda são bastante limitados em face das grandes necessidades dessas populações, e também são poucos, se comparados à utilização das estratégias individualizadas tradicionais da psicologia. Além disso, como já disseram Arcaro et al. (1999), muitos esforços realizados não têm sua eficácia adequadamente verificada, pois ainda são relativamente raros os estudos que, como o presente, avaliam de maneira sistemática os procedimentos implementados. Sendo assim, é preciso que sejam realizadas mais pesquisas suficientemente rigorosas, e espera-se que o êxito desta e de outras investigações anteriormente citadas (e.g. Costa, 1997; Gomes, 2004; Palha, 2001) possa incentivar outros profissionais a realizarem esforços nesse sentido.

\section{Referências}

Alves, M. (2004). Absenteísmo e sofrimento no trabalho. In J. R. Sampaio (Ed.), Qualidade de vida no trabalho e psicologia social (2. ed., pp. 343366). São Paulo, SP: Casa do Psicólogo.

Andrews, V. H., \& Hall, H. R. (1990). The effects of relaxation/imagery training on recurrent aphthous stomatitis: A preliminary study. Psychosomatic Medicine, 52, 526-535.

Arcaro, N. T. (1997). Imagens mentais em psicoterapia: Estudo empírico sobre sua eficácia e a importância da atitude e da habilidade do cliente em manejá-las (Tese de doutorado, Instituto de Psicologia, Universidade de São Paulo, SP, Brasil).

Arcaro, N. T., Herzberg, E., \& Trinca, W. (1999). O psicodiagnóstico infantil no atendimento psicológico a populações carentes. Revista Iberoamericana de Diagnóstico y Evaluación Psicológica, 1, 37-52.

Browne, M. W. (1995, 20 mar.). Computador faz "telepatia" que funciona. O Estado de São Paulo, p. G27.
Charlesworth, S. J. (2005). Understanding social suffering: A phenomenological investigation of the experience of inequality. Journal of Community e Applied Social Psychology, 15, 292-312.

Costa, L. F. (1997). Reuniões multifamiliares: Uma proposta de intervenção em psicologia clínica na comunidade (Tese de doutorado, Instituto de Psicologia, Universidade de São Paulo, SP, Brasil).

Eisenstadt, M., Price, B. A., \& Domingue, J. (1992). Software visualization as a pedagogical tool. Instructional Science, 21, 335-364.

Esteves, E. G. (2004). Sócio, trabalhador, pessoa: Negociações de entendimentos na construção cotidiana da autogestão de uma cooperativa industrial (Dissertação de mestrado, Instituto de Psicologia, Universidade de São Paulo, SP, Brasil).

Freud, S. (1972). A interpretação dos sonhos. In Edição "standard" brasileira das obras psicológicas completas de Sigmund Freud (Vols. 4-5, J. Salomão, Trad.). Rio de Janeiro, RJ: Imago. (Trabalho original publicado em 1900)

Gallbach, M. R. (1989). O arquétipo materno na gravidez: Um estudo de temas oníricos na abordagem junguiana (Dissertação de mestrado, Instituto de Psicologia da Universidade de São Paulo, SP, Brasil).

Garcia, M. L. P., \& Jorge, M. S. B. (2006). Vivência de trabalhadores de um centro de atenção psicossocial: Estudo à luz do pensamento de Martin Heidegger e Hans-Georg Gadamer. Ciência \& Saúde Coletiva, 11(3), 765-774.

Glikin, M. (2001). As imagens mentais como recurso em psicoterapia. Uma pesquisa de quatro abordagens. Gerald Epstein, Carl Simonton, Morris Netherton e Carl G. Jung (Dissertação de mestrado, Núcleo de Psicologia Clínica, Pontifícia Universidade Católica de São Paulo, SP, Brasil).

Gomes, M. S. R. (2004). Plano de ação participativa para a identificação da deficiência auditiva em crianças de 3 a 6 anos de idade de uma comunidade de baixa renda (Tese de doutorado, Faculdade de Medicina, Universidade de São Paulo, SP, Brasil).

Jung, C. G. (1987). O eu e o inconsciente. In Obras completas de C. G. Jung (6. ed., Vol. 7, t. 2, D. F. Silva, Trad.). Petrópolis, RJ: Vozes. (Trabalho original publicado em 1934) 
Kazdin, A. E. (1978). Covert modeling: The therapeutic application of imagined rehersal. In J. L. Singer \& K. S. Pope (Eds.), The power of human imagination: New methods in psychotherapy (pp. 255-277). New York: Plenum Press.

Konuma, C. M. (2005). O caso do assentamento Dom Tomás Balduíno, um estudo sobre a gestão do trabalho e das relações do trabalho no MST (Dissertação de mestrado, Faculdade de Economia, Administração e Contabilidade, Universidade de São Paulo, SP, Brasil).

Levis, D. J. (1993). The power of extrapolating basic laboratory principles: The behavioural-cognitive approach of implosive therapy. Behaviour Change, 10(3), 154-161.

Lima, A. (1990). Estudo sobre o método de experimentos com sonhos na concepção de Frederick Perls (Dissertação de mestrado, Instituto de Psicologia da Universidade de São Paulo, SP, Brasil).

Mattar, F. N. (2000). Pesquisa de mercado: Edição compacta (2. ed.). São Paulo, SP: Atlas.

Mendonça, L. G. T. (2005). Promoção da saúde: Análise do processo de um grupo de reeducação alimentar em um hospital universitário (Tese de doutorado, Instituto de Psicologia, Universidade de São Paulo, SP, Brasil).

Molina, R. (2007). A pesquisa-ação / investigação-ação no Brasil: mapeamento da produção (1966-2002) e os indicadores internos da pesquisa-ação colaborativa (Tese de doutorado, Faculdade de Educação, Universidade de São Paulo, SP, Brasil).

Palha, P. F. (2001). Vivências do cotidiano: A promoção da saúde como um exercício de cidadania no programa de integração comunitária da Vila Tibério - Ribeirão Preto/SP (Tese de doutorado, Escolas de Enfermagem, Universidade de São Paulo, Ribeirão Preto, SP, Brasil).

Rancour, P. (1991). Guided imagery: Healing when curing is out of the question. Perspectives in Psychiatric Care, 27(4), 30-33.

Raposo, J. V., Costa, G., \& Carvalhal, I. M. (2001). Imagética kinetica e mental em praticantes de desportos coletivos e individuais. Estudos de Psicologia (Campinas), 18(1), 58-75.
Richardson, A. (1983). Imagery: Definition and types. In A. A. Sheikh (Ed.), Imagery: Current theory, research, and application (pp. 3-41). New York: John Wiley.

Romme, A. G. L. (2004). Action research, emancipation and design thinking. Journal of Community e Applied Social Psychology, 14, 495-499.

Samuels, M., \& Samuels, N. (1975). Seing with the mind's eye: The history, techniques and uses of visualization. New York: Random House.

Selltiz, C., Wrightsman, L. S., \& Cook, S. W. (1987). Métodos de pesquisa nas relações sociais: Vol. 1. Delineamentos de pesquisa (2. ed.). São Paulo, SP: EPU.

Silva, R. C. (2002). Metodologias participativas para trabalhos de promoção de saúde e cidadania. São Paulo, SP: Vetor.

Velásquez, C. S. C. (2002). Da formação de grupos à ação coletiva: Uma análise com grupos de jovens do assentamento rural da Fazenda Ipanema - Iperó-SP (Dissertação de mestrado, Escola Superior de Agricultura Luiz de Queiroz, Universidade de São Paulo, Piracicaba, SP, Brasil).

Vizzotto, M. M. (2003). O método clínico e as intervenções na saúde psicológica da comunidade. In V. B. Oliveira \& K. Yamamoto (Eds.), Psicologia da Saúde: Temas de reflexão e prática (pp. 137-152). São Bernardo do Campo, SP: Universidade Metodista de São Paulo.

Wiesenfeld, E. (2001). Tendencias y perspectivas de desarrollo en Psicología Ambiental. In E. T. O. Tassara (Ed.), Panoramas interdisciplinares para uma psicologia ambiental do urbano (pp. 27-49). São Paulo, SP: Editora da Pontificia Universidade Católica de São Paulo.

Wolpe, J. (1973). The practice of behavior therapy $\left(2^{\text {nd }}\right.$ ed.). New York: Pergamon Press. 